\title{
Tasks performance by registered nurses and care assistants in nursing homes: A quantitative comparison of survey data
}

\author{
Louis Paquay ${ }^{\mathrm{a}}$, Jan De Lepeleire ${ }^{\mathrm{a}}$, Koen Milisen ${ }^{\mathrm{b}, \mathrm{c}}$, Michel Ylieff ${ }^{\mathrm{d}}$, \\ Ovide Fontaine ${ }^{\mathrm{d}}$, Frank Buntinx ${ }^{\mathrm{a}, \mathrm{e}, *}$ \\ ${ }^{a}$ Department of General Practice, Katholieke Universiteit Leuven, Leuven, Belgium \\ ${ }^{\mathrm{b}}$ Centre for Health Services and Nursing Research, Katholieke Universiteit Leuven, Leuven, Belgium \\ ${ }^{\mathrm{c}}$ Department of Geriatric Medicine, University Hospitals of Leuven, Leuven, Belgium \\ ${ }^{\mathrm{d}}$ Faculty of Psychology and Educational Sciences, Université de Liège, Liège, Belgium \\ ${ }^{\mathrm{e}}$ Department of General Practice, Universiteit Maastricht, Maastricht, The Netherlands
}

Received 2 August 2006; received in revised form 25 January 2007; accepted 3 February 2007

\begin{abstract}
Objectives: To examine the care tasks performed for residents of Belgian care institutions for older people and the association between the performance of care tasks by persons of different staffing categories (registered nurses (RN) and care assistants (CA)) and the characteristics (the dependency level and the diagnosis of dementia) of the residents. Study design and setting: Survey on the care for residents, aged 65 or over, living in 26 care institutions for aged people. Main outcome measures: Separate bivariate comparisons of care time spent on residents with and without dementia and bivariate comparisons of care time spent on six task categories on residents of different dependency levels were performed. The median number of minutes over seven days (mosd) and the inter quartile range (IQR) are presented as summary measures. The proportion of the time spent by RNs and CAs per resident and per task category was calculated.

Results: Time spent was highest on primary care tasks (34,554 mosd; 48.7\%), followed by in order of time spent, supportive tasks $(10,845$ mosd; $15.3 \%)$, logistic tasks (10,697 mosd; $15.1 \%)$, practical nursing procedures ( 8689 mosd; $12.2 \%$ ), administrative tasks (3357 mosd; $4.7 \%$ ) and communication tasks (2814 mosd; $4.0 \%)$. Overall there was no significant difference between the total time spent by RNs (median $=190$ mosd; IQR 105-334) and the total time spent by CAs (median $=196$ mosd; IQR 91-331; $p=0.89$ ). RNs were spending significantly more time than CAs in practical nursing procedures, communication tasks and administrative tasks.

Conclusions: There was a sharp task demarcation between RNs and CAs in the three less frequent task categories. There was no indication that RNs were delegating tasks to CAs.
\end{abstract}

(C) 2007 Elsevier Ltd. All rights reserved.

Keywords: Registered nurse; Care assistant; Nursing home; Dependency; Dementia

\footnotetext{
*Corresponding author. Department of General Practice, Katholieke Universiteit Leuven, Leuven, Belgium. Tel.: + 3216337493; fax: +3216337480 .

E-mail address: frank.buntinx@med.kuleuven.be (F. Buntinx).
} 
What is already known about the topic?

- In nursing homes, the rules for the delegation of tasks by registered nurses to care assistants are inadequately defined.

- This lack of clarity gives cause for tension and ambiguity about each other's role.

\section{What this paper adds}

- Because the Belgian staffing regulations require that nursing homes employ almost equal FTEs of registered nurses and care assistants, professionals of both disciplines spent similar amounts of time in the categories of primary care, logistic tasks and supportive tasks.

- The task demarcation between registered nurses and care assistants in institutions for aged persons was limited to task categories in which time spending was low: practical nursing procedures, communication and administrative tasks.

- Registered nurses were not focusing on residents with dementia or residents with higher dependency levels. They were not delegating the care for residents without dementia or residents with lower dependency to care assistants.

\section{Introduction}

\subsection{Background}

In Belgium, care institutions for older persons are paid for partly by the resident and partly by the national social security system. Prices are largely fixed by social security regulations. Functional assessment of a person's abilities with regard to the activities of daily living (ADL) is used for determining staffing requirements on the one hand and funding of nursing care on the other. Federal health regulations for low care (residential homes) and major care institutions (nursing homes) specify in great detail the required number of registered nurses (RN) and care assistants (CA) relative to the global weighted dependency level of all residents admitted to the institution (Table 1). As an example, we calculated the required full-time equivalent (FTE) RNs and CAs for a fictitious nursing home where 75 residents are taken care for: 30 residents with level B dependency and 45 residents with level $\mathrm{C}$ dependency. According to Table 1, the minimal required FTE of nursing staff for the nursing home is $12.5 \mathrm{RNs}((5 \times(30)$ $30))+(5 \times(45 / 30))=12.5)$ and 14 CAs $((5 \times(30 /$ $30)+(6 \times(45 / 30))=14)$. For this fictitious nursing home, the ratio of required FTE RNs over required
Table 1

Nursing staffing regulations for care institutions for older people in Belgium: the required full-time equivalent registered nurses (RN) and care assistants (CA) per 30 residents of the institution

\begin{tabular}{|c|c|c|c|c|c|c|c|c|}
\hline \multirow{3}{*}{$\begin{array}{l}\text { Professional } \\
\text { disciplines }\end{array}$} & \multicolumn{5}{|c|}{ Residential facilities } & \multicolumn{3}{|c|}{ Nursing homes } \\
\hline & \multicolumn{5}{|c|}{ Dependency level $^{\mathrm{a}}$} & \multicolumn{3}{|c|}{ Dependency level $^{\mathrm{a}}$} \\
\hline & $\mathrm{O}$ & A & B & $\mathrm{C}$ & $\mathrm{Cd}$ & B & $\mathrm{C}$ & $\mathrm{Cd}$ \\
\hline $\mathrm{RN}$ & 0.25 & 1.2 & 2.1 & 4.1 & - & 5 & 5 & - \\
\hline $\mathrm{CA}$ & - & 0.8 & 4.0 & 5.06 & 1 & 5 & 6 & 0.5 \\
\hline
\end{tabular}

The level Cd stands for dependency level $\mathrm{C}$ and a score $\geqslant 3$ for 'orientation in time' or 'orientation in the living environment'.

${ }^{a}$ According to the Belgian Activities of Daily Living (ADL) Evaluation Scale: $\mathrm{O}$ is the lowest dependency level; $\mathrm{C}$ is the highest dependency level.

FTE CAs is $0.89(12.5 / 14)$. Belgian RNs received 3 years of nursing education. CAs may have had a variety of short courses.

Funding of nursing care in a Belgian care institution for older persons is also based on the global weighted dependency level of all residents in the institution. Historical data from previous years are used for the calculation of the annual subsidy for the institution's costs of nursing staff.

Because of its important role in the Belgian social security regulations, the functional ADL assessment should be a valid indicator for the required professional qualification-mix and the task performance by RNs and CAs in care institutions.

Several authors reported ambiguity and tensions about the task demarcation between RNs and CAs in nursing homes. Defining and limiting the roles of RNs and delegating tasks to CAs was problematic, and there were concerns about the ease with which some patientrelated tasks were moved to nursing assistants (Perry et al., 2003; Rhéaume, 2003). Consequently, RNs undertook everything and anything within the nursing home. By contrast, CAs defined their role in terms of what they were not allowed to do (Perry et al., 2003). In a UK National Health Service study, Nursing Auxiliaries/ Assistants (NA) and Health Care Assistants (HCA) were engaging widely in 'nursing' duties and 'more technical and advanced tasks': e.g. giving drugs without supervision (Thornley, 2000). The major experience of NAs and HCAs was that they undertook the same or similar work as a RN' sometimes or frequently. Only a minority felt that they 'rarely or never' substituted for registered staff. In a Canadian study in rural nursing homes, the nursing aides were less likely than nurses to agree that they had enough time to do their work 
(Morgan et al., 2002). They struggled to meet the physical care needs and were distressed by their inability to adequately address psychosocial needs. Another example of such tension was found in a US focus group study in which it was confirmed that nurses and certified nursing assistants (CNA) had different relationships with residents and were aware of different pain cues (Clark et al., 2004). The communication was strained around issues of pain with CNAs and nurses holding divergent views about their ability to work together to address residents' pain.

Although the Belgian social security regulations concerning staffing resources and reimbursement levels were specified in great detail, we found few studies examining the appropriateness of reimbursement levels according to the actual times worked by RNs and CAs in Belgian care institutions for older people.

In the study 'Activity and costs analysis in relation to the care profile' (Cokelaere, 1997), the appropriateness of reimbursement levels according to the actual times worked by $\mathrm{RNs}$ and CAs was investigated. In this unpublished study, data on care processes were collected during 7 days on 197 randomly selected residents of 16 institutions in the province of West-Flanders. The mean total care time for residents with level $\mathrm{O}$ dependency was $37 \mathrm{~min} /$ day, for level A it was $48 \mathrm{~min}$, for level B $62 \mathrm{~min}$, for level $\mathrm{C} 90 \mathrm{~min}$ and for level $\mathrm{Cd}$ it was $85 \mathrm{~min} /$ day (Cokelaere, 1997).

In the survey 'Time for Care', RNs of 19 Belgian institutions reported spending $44-52 \%$ of their work shift time in primary care tasks, $13-19 \%$ in practical nursing procedures, $11-17 \%$ in logistic tasks, $5-8 \%$ in supportive tasks, $4-5 \%$ in communication tasks, $4-8 \%$ in administrative tasks and $5-6 \%$ in other tasks (Mendonck et al., 2000). For CAs this survey yielded the following pattern: $54 \%$ in primary care tasks, $4-8 \%$ in practical nursing procedures, $20-21 \%$ in logistic tasks, $5-10 \%$ in supportive tasks, $4 \%$ in communication tasks, $3-4 \%$ in administrative tasks and $5-6 \%$ in other tasks.

Since the introduction of the Belgian federal health care regulations in the early 1990s, there have been discussions about adequate funding and the required professional qualification-mix for care institutions. Cost savings vs. quality of care are the main arguments in the discussion, but specific information about the contribution of different professional disciplines was lacking: in the study by Cokelaere the personnel's profession was not taken into account and in the study by Mendonck et al. the resident's dependency level was not considered.

\subsection{Objectives}

The objective of the present study was to investigate whether the performance of care tasks by persons of different staffing categories was associated with the dependency level and the diagnosis of dementia of the residents. The study was designed to bridge the gap between the previous studies by Cokelaere (1997) and Mendonck et al. (2000). Therefore, the care tasks performed for residents of Belgian care institutions for older people were analyzed according to the staffing category (RN and $\mathrm{CA}$ ) and according to the resident's characteristics.

The research questions were:

1. To what extent and in which task categories is there a clear task demarcation between RNs and CAs?

2. Do RNs and CAs spend more time on residents suffering from dementia or on residents with higher dependency?

3. Are RNs delegating the care for residents not having dementia or residents with lower dependency levels to CAs?

\section{Methods}

\subsection{Subjects and sample}

Initially, all consenting residents, 65 years of age and older, of 26 Belgian care institutions were eligible for inclusion. The residents were all eligible for the Qualidem study on assessment instruments for the care of older persons with dementia. All study subjects were selected using a three-stage selection procedure, which was based on standardized assessment results and random allocation. The selection procedure is described in detail elsewhere (Paquay et al., 2004). All subjects or their proxies were asked for written informed consent by the GP or nurse who had included the subject, using a protocol approved by the ethical committee of the Leuven University Medical School. In accordance with Belgian privacy legislation, all study subjects remained anonymous to the investigators until informed consent had been given.

\subsection{Instruments}

The Belgian ADL Evaluation Scale (Arnaert and Delesie, 1999) is an adaptation of the 'Index of ADL' (Katz et al., 1963). The adapted assessment tool evaluates the six original domains of the 'Index of ADL': bathing, dressing, transfer, toileting, continence, and eating. In contrast to the original scale, each function has four (no assistance, with assistive device, assistance, total dependency) instead of three (no assistance, limited assistance, total dependency) score categories. Two additional items about orientation in time and orientation in the living environment are scored from 1 to 5 , a higher score indicating a higher 
degree of disorientation. The total scale score can easily be deduced with the aid of a Boolean logic algorithm into one of four hierarchical levels of dependency, which are coded with the capitals $\mathrm{O}$ (lowest dependency), A, B, and C (highest dependency) (Arnaert and Delesie, 1999).

The Clinical Dementia Rating (CDR; Hughes et al., 1982; Morris, 1993) evaluates six domains of functioning: memory; orientation; judgement and problem solving; community affairs; home and hobbies; and personal care. CDR ratings were 0 for healthy people, 0.5 for questionable dementia and 1,2 and 3 for mild, moderate and severe dementia respectively. The total CDR rating was derived from the sum of boxes and represents an aggregate score for each individual.

The weighted index of comorbidity (Charlson et al., 1987) is a method of classifying comorbid conditions which might alter the risk of mortality in longitudinal studies. It takes into account the number and seriousness of comorbid disease.

The CAMDEX-R (Roth et al., 1986) was used for formal support for five diagnostic categories: dementia, delirium, depression, mild cognitive impairment (MCI) or none of these.

The actual nursing care time was recorded on a checklist of 82 nursing tasks which covered six types of resident-related activities (Mendonck et al., 2000): primary care tasks, practical nursing procedures, logistic tasks, administrative tasks, communicative tasks and supportive tasks. Examples of the six task categories are presented in Table 2. The list of care tasks was made by consensus with participants of both professions and from all Belgian health care sectors. The authors qualified some tasks as direct patient care (e.g. hygienic care); other tasks were qualified as indirect patient care (e.g. meal preparation). Originally, the list also covered a list of unit-related tasks (e.g. coordination of activities, communication not related to residents, etc.). In the present study, only the resident-related direct and indirect patient care tasks were used. Distinction between primary care tasks and practical nursing procedures is made by several Belgian laws and regulations. According to these regulations, CAs are not allowed to perform practical nursing procedures.

Table 2

Examples of the tasks in the six task categories

\section{Primary care tasks}

Hygienic care in bed

Help with hygienic care

Hair, nails, teeth, shaving, ...

Positioning

Help with transfers in and out of bed

Help with mobility

Stimulation of mobility

Transfers inside the house/institution

Transfers outside the house/institution

Help with feeding

Help with use of bedpan, toilet chair

Assistance with toileting

Change diapers

Assistance with vomiting

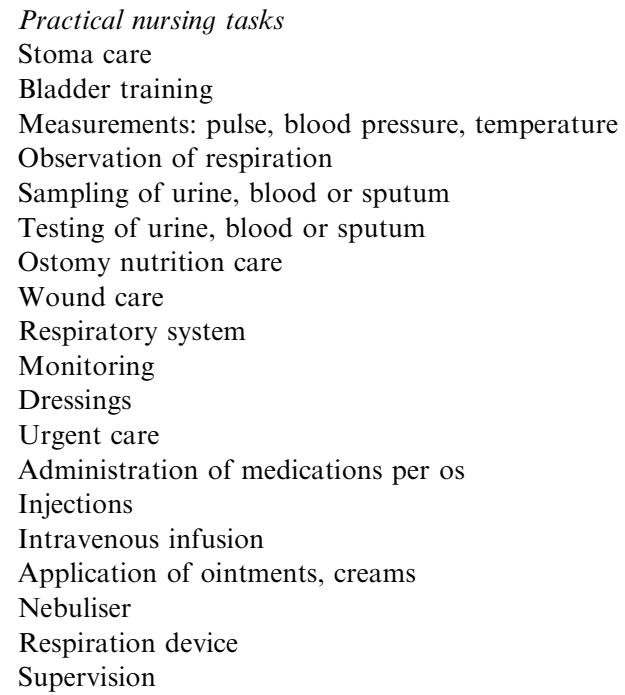

\section{Administrative tasks}

Note down observations in the resident file

Document the resident's need for care and the care plan 


\subsection{Data collection}

The purpose of the data collection was to make a detailed inventory of all resident-related tasks performed by RNs and CAs during seven consecutive days. In order to maximize the opportunities for RNs and CAs to report the tasks performed during their shift, RNs and CAs used separate but identical forms (different colours). Both professional disciplines used one form for the morning shift and a second form for the afternoon and evening shift, making up a total of four forms per resident per day. All activities between 7:00 AM and 7:00 PM were reported. Shortly after they had carried out a task and using the standardized task lists, RNs and CAs noted the time (in minutes) they had spent performing a specific task for an individual resident.

The subject's clinical condition was evaluated by the subject's charge nurse using the standardised assessment instruments (e.g. CDR, Charlson's weighted index of comorbidity).

\subsection{Statistical analysis}

The median and the inter quartile range (IQR) of the total care time per resident in minutes over seven days (mosd) are presented as summary measures (Table 4). The care time was also specified in detail for each profession and for groups of residents with the same dependency level or with and without dementia. The proportion of time spent by RNs and CAs per resident and per task category was calculated (Table 5). For example, the proportion of primary care tasks performed by RNs was calculated as follows: in the numerator was the time spent by $\mathrm{RNs}$ on primary care tasks; in the denominator was the total time spent on primary care tasks by RNs and CAs. Within the task category and for each resident the sum of the two proportions (one proportion for RNs and one proportion for CAs) adds up to 1. Therefore, only the proportions for RNs are presented in Table 5 .

Three strategies were used to compare the task performance of RNs and CAs.

In the first strategy, the Wilcoxon signed ranks test was used for pairwise comparison of the time spent by RNs and the time spent by CAs within each resident (Siegel and Castellan, 1988). This analysis was performed for each task category and for the overall time.

In the second strategy, the association between the time spent and the resident's characteristics was investigated within each profession separately, using the Kruskal-Wallis test to test the association with the dependency levels and using the Wilcoxon test to test the association with the dementia status (Siegel and Castellan, 1988). Similarities or differences between RNs and CAs regarding these associations are readily visible in Table 4.
In the third strategy, the proportional contributions of RNs and CAs to the total time spent per resident in each task category were analyzed to investigate whether there was delegation of tasks from RNs towards CAs depending on the dependency level and the dementia status (Table 5). The Kruskal-Wallis test was used to test the association with the dependency level and the Wilcoxon test was used to test the association with the dementia status (Table 5).

A $p$-value $<.05$ was considered statistically significant. All tests were two-sided. The SAS System 8.2 software was used for statistical analysis.

\section{Results}

\subsection{Sample}

From February to July 2002 data were collected for 123 residents of 26 mixed low and high care institutions. Ten institutions were public institutions, 13 institutions were owned by a non-profit organization and three institutions were owned by a for-profit organization. One hundred and twenty residents had a follow-up of 7 days and 1 resident had a follow-up of 6 days. Two residents, one with only one day follow-up and one with only two days follow-up were excluded from analysis. The final analysis was performed on data from the remaining 121 residents who had at least 6 days of follow-up. Of the 121 study subjects, 48 (40\%) were living in a public institution, $63(52 \%)$ in an institution owned by a private non-profit organization and 10 subjects $(8 \%)$ were residing in an institution owned by a private for-profit organization.

Subjects ranged in age from 66 years to 101 years, with a mean age of 83.4 years $(\mathrm{SD}=7.2)$ and fitted normal density distribution $(p=0.12)$. There were 100 residents with dementia and 21 residents not suffering from dementia. There were no statistically significant differences between subjects with and without dementia for the variables age $(p=0.23)$, sex $(p=1.0)$ or the diagnosis of depression (Table 3). Subjects with dementia were significantly more dependent, had more comorbidity and had a higher CDR score.

\subsection{Total care time per task category}

The amount of care time recorded for all 121 residents together was 70,956 mosd. Time spent was highest on primary care tasks $(34,554$ mosd; $48.7 \%)$, followed byin order of the time spent-supportive tasks $(10,845$ mosd; $15.3 \%)$, logistic tasks (10,697 mosd; $15.1 \%)$, practical nursing procedures (8689 mosd; $12.2 \%$ ), administrative tasks (3357 mosd; 4.7\%) and communication tasks (2814 mosd; 4.0\%). 
Table 3

Characteristics of residents of care institutions. Statistical tests were performed to test for differences between subjects with and without dementia

\begin{tabular}{|c|c|c|c|c|}
\hline & $\begin{array}{l}\text { Study } \\
\text { population } \\
n=121\end{array}$ & $\begin{array}{l}\text { Subjects with } \\
\text { dementia } \\
n=100\end{array}$ & $\begin{array}{l}\text { Subjects without } \\
\text { dementia } \\
n=21\end{array}$ & $p$-value \\
\hline Mean age (SD) & $83.4(7.2)$ & $83.8(8.5)$ & $81.7(6.9)$ & $0.23^{*}$ \\
\hline Female sex $(\%)$ & $100(82.6 \%)$ & $82(82.0 \%)$ & $18(85.7 \%)$ & $1.0^{* *}$ \\
\hline \multicolumn{5}{|l|}{ Belgian ADL } \\
\hline Evaluation Scale ${ }^{\mathrm{a}}(\%)$ & $17(14.1 \%)$ & $9(9.0 \%)$ & $8(38.1 \%)$ & $<0.001 * * *$ \\
\hline $\mathrm{O}$ & $17(14.1 \%)$ & $12(12.0 \%)$ & $5(23.8 \%)$ & \\
\hline A & $27(22.3 \%)$ & $23(23.0 \%)$ & $4(19.1 \%)$ & \\
\hline $\mathrm{B}$ & $60(49.6 \%)$ & $56(56.0 \%)$ & $4(19.1 \%)$ & \\
\hline \multicolumn{5}{|l|}{$\mathrm{C}$} \\
\hline Depression $(\%)$ & $26(21.5 \%)$ & $20(20.0 \%)$ & $6(28.6 \%)$ & $0.39^{* *}$ \\
\hline Charlson's index of comorbidity ${ }^{\mathrm{b}}$ & $2(1-3)$ & $2(1-3)$ & $1(1-2)$ & $0.02 * * *$ \\
\hline Clinical Dementia Rating scale ${ }^{\mathrm{b}}$ & $14.8(8.5-20)$ & $16.5(12-21)$ & $6.3(3-9)$ & $<0.001 * * *$ \\
\hline
\end{tabular}

*Student's $t$-test.

**Fisher's Exact test.

$* * *$ Wilcoxon test.

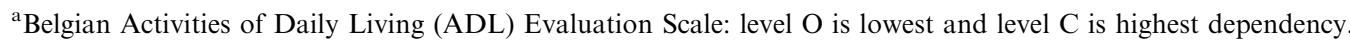

${ }^{\mathrm{b}}$ Values followed by numbers in parentheses are medians, with the 25 th and 75 th percentiles shown inside the parentheses.

\subsection{Task demarcation between RNs and CAs}

Overall there was no significant difference between the total time spent by RNs (median $=190$ mosd; IQR 105-334) and the total time spent by CAs (median = 196 mosd; IQR 91-331; $p=0.89$ ).

RNs spent significantly more time than CAs on practical nursing tasks (32 vs. 9 mosd; $p<0.001)$, communication tasks (4 vs. $0 \operatorname{mosd} ; p=0.04)$ and administrative tasks (7 vs. 1 mosd; $p<0.001$ ). There was no difference between RNs and CAs in time spent on primary care tasks (99 vs. $102 \operatorname{mosd} ; p=0.21$ ), logistic tasks ( 21 vs. $26 \operatorname{mosd} ; p=0.10$ ), and supportive tasks ( 15 vs. 7 mosd; $p=0.47$ ).

\subsection{Time spent on care tasks and the resident's dependency level}

The total time spent by RNs was significantly higher on residents with higher dependency (median for level $\mathrm{O}=81$ mosd, for level $\mathrm{A}=132 \mathrm{mosd}$, for level $\mathrm{B}=$ 148 mosd, for level $\mathrm{C}=255$ mosd; $p<0.001$; Table 4). There also was a significant relation between the total time spent by CAs and increasing dependency levels $(p=0.02)$, although CAs spent more time on residents of level A (median $=195$ mosd) than on residents of level $\mathrm{B}($ median $=174$ mosd $)$.

The time spent by RNs on primary care tasks and logistic tasks was significantly higher for residents with higher dependency levels. A significant difference was combined with an imperfect association between the time spent and the dependency levels for RNs perform- ing practical nursing procedures and administrative tasks and for CAs performing primary care tasks. There were no significant differences in time spent between residents of different dependency levels for RNs performing supportive tasks or communication tasks and for CAs performing practical nursing procedures, logistic tasks, supportive tasks, communication tasks or administrative tasks.

\subsection{Time spent and the resident's dementia status}

The total time spent by RNs on residents with dementia (median $=215$ mosd) was significantly higher than on residents without dementia (median $=$ 110 mosd; $p<0.010$; Table 4). For CAs the difference in total time spent for residents with (median $=$ 196 mosd) and without dementia (median $=142$ mosd; $p=0.34$ ) was not significant.

RNs spent significantly more time caring for residents with dementia than for residents without dementia when performing primary care tasks, practical nursing procedures, and logistic tasks. There was no significant difference in time spent between residents with and without dementia for RNs performing supportive tasks, communication tasks or administrative tasks or for CAs in any of the task categories.

\subsection{Proportional contributions of RNs and CAs}

The analysis of the separate proportional contributions of RNs within each task category and for the total time spent is presented in Table 5. Overall there was no 
Table 4

Time in minutes (median and IQR) spent in six task categories and total time spent by registered nurses and care assistants over a period of seven consecutive days in residents of Belgian nursing homes

\begin{tabular}{|c|c|c|c|c|c|c|c|c|c|}
\hline \multirow{3}{*}{$\begin{array}{l}\text { Task categories and } \\
\text { professions }\end{array}$} & & \multicolumn{5}{|c|}{ Dependency level*** } & \multicolumn{3}{|c|}{ Dementia status } \\
\hline & & $\mathrm{O}$ & A & B & $\mathrm{C}$ & \multirow[b]{2}{*}{$p$-value* } & \multirow{2}{*}{$\begin{array}{l}\text { Subjects } \\
\text { with } \\
\text { dementia } \\
\begin{array}{l}\text { Median } \\
\text { (IQR) }\end{array}\end{array}$} & \multirow{2}{*}{$\begin{array}{l}\text { Subjects } \\
\text { without } \\
\text { dementia }\end{array}$} & \multirow[b]{2}{*}{$p$-value $* *$} \\
\hline & & $\begin{array}{l}\text { Median } \\
\text { (IQR) }\end{array}$ & $\begin{array}{l}\text { Median } \\
\text { (IQR) }\end{array}$ & $\begin{array}{l}\text { Median } \\
(\mathrm{IQR})\end{array}$ & $\begin{array}{l}\text { Median } \\
\text { (IQR) }\end{array}$ & & & & \\
\hline \multirow[t]{2}{*}{ Primary care tasks } & RNs & $7(0-25)$ & $46(18-88)$ & $76(54-107)$ & $139(102-248)$ & $<0.001$ & $104(54-185)$ & $57(0-99)$ & 0.006 \\
\hline & CAs & $20(0-53)$ & $77(20-146)$ & $75(51-135)$ & $155(91-272)$ & $<0.001$ & $109(55-181)$ & $60(10-165)$ & 0.15 \\
\hline \multirow{2}{*}{$\begin{array}{l}\text { Practical nursing } \\
\text { procedures }\end{array}$} & RNs & $19(10-28)$ & $28(18-51)$ & $22(11-48)$ & $37(26-67)$ & 0.002 & $35(18-61)$ & $20(14-35)$ & 0.02 \\
\hline & CAs & $7(4-13)$ & $10(2-14)$ & $8(5-14)$ & $10(1-27)$ & 0.99 & $10(2-17)$ & $8(2-13)$ & 0.48 \\
\hline \multirow[t]{2}{*}{ Logistic tasks } & RNs & $0(0-15)$ & $11(4-19)$ & $21(3-36)$ & $34(19-62)$ & $<0.001$ & $23(11-55)$ & $7(0-18)$ & 0.003 \\
\hline & CAs & $9(3-36)$ & $19(3-75)$ & $21(5-76)$ & $40(15-81)$ & 0.13 & $29(10-75)$ & $7(0-64)$ & 0.07 \\
\hline \multirow[t]{2}{*}{ Supportive tasks } & RNs & $28(2-55)$ & $12(2-34)$ & $16(1-47)$ & $15(2-40)$ & 0.95 & $13(1-47)$ & $26(9-37)$ & 0.48 \\
\hline & CAs & $10(5-30)$ & $5(0-90)$ & $6(0-23)$ & $7(0-59)$ & 0.70 & $7(0-40)$ & $5(0-34)$ & 0.79 \\
\hline \multirow{2}{*}{$\begin{array}{l}\text { Communication } \\
\text { tasks }\end{array}$} & RNs & $4(0-10)$ & $3(0-10)$ & $4(0-7)$ & $7(0-22)$ & 0.53 & $5(0-15)$ & $3(0-12)$ & 0.23 \\
\hline & CAs & $0(0-7)$ & $1(0-13)$ & $0(0-1)$ & $0(0-10)$ & 0.29 & $0(0-10)$ & $0(0-0)$ & 0.08 \\
\hline \multirow[t]{2}{*}{ Administrative tasks } & RNs & $3(0-14)$ & $6(1-14)$ & $5(2-8)$ & $12(5-23)$ & 0.005 & $8(4-18)$ & $6(0-14)$ & 0.24 \\
\hline & CAs & $2(0-9)$ & $0(0-3)$ & $0(0-2)$ & $2(0-10)$ & 0.21 & $1(0-7)$ & $0(0-2)$ & 0.34 \\
\hline \multirow{2}{*}{$\begin{array}{l}\text { Total care time in six } \\
\text { task categories }\end{array}$} & RNs & $81(52-110)$ & $132(77-236)$ & $148(87-295)$ & $255(177-492)$ & $<0.001$ & $215(116-377)$ & $110(81-198)$ & 0.01 \\
\hline & CAs & $89(53-142)$ & $195(82-346)$ & $174(70-225)$ & $236(140-481)$ & 0.02 & $196(99-358)$ & $142(66-299)$ & 0.34 \\
\hline
\end{tabular}

The Kruskal-Wallis test was used to test for differences between residents with different dependency levels; the Wilcoxon test was used to test for differences between residents with and without dementia.

Professions: RNs = registered nurses; CAs = care assistants; IQR = interquartile range: 25 th percentile-75th percentile.

*Kruskal-Wallis test.

**Wilcoxon test.

***Dependency levels according to the Belgian Activities of Daily Living (ADL) Evaluation Scale: level O dependency is the lowest and level $\mathrm{C}$ dependency is the highest dependency level.

significant difference between the proportion of the total time spent on different dependency levels by RNs (or CAs) $(p=0.57$; Table 5). There was also no significant difference between the proportion of the total time spent on residents with or without dementia by either RNs or CAs $(p=0.33$; Table 5$)$.

In Table 5 there is only one significant $p$-value indicating that the proportion of time spent on communication tasks by $\mathrm{RNs}$ is significantly different for residents of different dependency levels $(p=0.03)$, and by definition the same conclusion is true for CAs. All other $p$-values indicated non-significant differences in proportional contributions of RNs and CAs among different dependency levels and between residents with and without dementia.

\section{Discussion}

In the present study, the total amount of time spent on resident-related tasks was not different for RNs and
CAs. There was a sharp task demarcation between RNs and CAs in the three task categories that contributed least to the total time spent: RNs were spending significantly more time than CAs in practical nursing procedures, communication tasks and administrative tasks. Since, by law, RNs are exclusively permitted to carry out practical nursing procedures, this result was to be expected for the time spent in this task category. With regard to communication tasks, the contribution of CAs was probably extremely low because in this study, communication was defined as formal communication with family members, the GP, etc.

There was no indication that RNs were delegating the other tasks to CAs: primary care tasks, logistic tasks and supportive tasks, which were the tasks that constituted almost $80 \%$ of the resident-related care time. These conclusions support the view formulated by Perry et al. (2003) that RNs had difficulty defining and limiting their roles and consequently they undertook everything and anything within the nursing home: instead of delegating some tasks which required less professional competency 
Table 5

Median proportion of the care time spent by registered nurses in six task categories and of the total care time spent by registered nurses in residents of Belgian nursing homes

\begin{tabular}{|c|c|c|c|c|c|c|c|c|}
\hline \multirow[t]{2}{*}{ Task categories } & \multicolumn{5}{|c|}{ Dependency level*** } & \multicolumn{3}{|c|}{ Dementia status } \\
\hline & $\mathrm{O}$ & A & $\mathrm{B}$ & $\mathrm{C}$ & $p$-value* & $\begin{array}{l}\text { Subjects with } \\
\text { dementia }\end{array}$ & $\begin{array}{l}\text { Subjects without } \\
\text { dementia }\end{array}$ & $p$-value ${ }^{* *}$ \\
\hline Primary care tasks & 0.41 & 0.29 & 0.50 & 0.47 & 0.53 & 0.47 & 0.36 & 0.12 \\
\hline $\begin{array}{l}\text { Practical nursing } \\
\text { procedures }\end{array}$ & 0.62 & 0.87 & 0.63 & 0.79 & 0.24 & 0.77 & 0.69 & 0.52 \\
\hline Logistic tasks & 0.09 & 0.28 & 0.50 & 0.49 & 0.11 & 0.49 & 0.37 & 0.24 \\
\hline Supportive tasks & 0.56 & 0.44 & 0.68 & 0.65 & 0.52 & 0.64 & 0.72 & 0.61 \\
\hline Communication tasks & 0.78 & 0.27 & 1.00 & 0.94 & 0.03 & 0.91 & 1.00 & 0.31 \\
\hline Administrative tasks & 0.45 & 0.89 & 1.00 & 0.77 & 0.16 & 0.77 & 0.76 & 0.59 \\
\hline Total care time & 0.45 & 0.36 & 0.46 & 0.52 & 0.57 & 0.51 & 0.46 & 0.33 \\
\hline
\end{tabular}

The Kruskal-Wallis test was used to test for differences between residents with different dependency levels; the Wilcoxon test was used to test for differences between residents with and without dementia.

*Kruskal-Wallis test.

**Wilcoxon test.

***Dependency levels according to the Belgian Activities of Daily Living (ADL) Evaluation Scale: level O dependency is the lowest and level $\mathrm{C}$ dependency is the highest dependency level.

to CAs (e.g. supportive tasks or logistic tasks), RNs carried out these tasks to the same extent as CAs. These findings also illustrate the effects of the Belgian staffing regulations for nursing homes, which stipulated in detail almost equal numbers of FTEs of RNs and CAs. As a consequence of these regulations, the presence of RNs in the nursing homes was almost equal to the presence of CAs, and the contribution of the RNs to task categories, such as primary care tasks, logistic tasks and supportive tasks, was substantial and similar to the contribution of the CAs.

There was evidence that RNs and CAs were spending more time on residents suffering from dementia or on residents with higher dependency. It might have been anticipated that RNs had to make choices regarding delegation of care to less dependent subjects or to subjects who were not suffering from dementia. However, since the proportion of time spent by RNs (and also CAs) was not associated with the dependency levels or the dementia status, it may be concluded that RNs were not delegating tasks to CAs according to the resident's dependency or dementia status.

Due to the small size of the study and its exploratory nature, these results should be interpreted cautiously.

One problem of analyzing the study was that persons with and without dementia were significantly different with regard to the level of both dependency and comorbidity (Table 3). Therefore, the analysis of the relative contribution of the dementia status and the dependency level (and their interaction term) in a statistical model did not reveal a comprehensive explanation of the relative impact of these characteristics (and their interaction term) on the performance of tasks by RNs and CAs.

The associations between the task performance and the subject's dependency level may have been influenced by the charge nurse's opinion, because the charge nurse performed the clinical assessment and she was at the same time participating in the subject's nursing care. However, this influence may be limited, because tasks were recorded throughout the day, mostly from 7:00 AM until 7:00 PM, and many nurses contributed to the care tasks recorded per resident.

Another limitation of the study was the focus on task performance. A lot of institutions promote personoriented nursing care rather than task-oriented nursing care. Perhaps, other instruments would have been better adapted to study person-oriented care processes, taking into account the formal delegation of tasks from RNs to CAs.

Under-recording may also be a limitation of the study. The feedback was given to the investigators that a consistent recording process was sometimes lacking. Some RNs and CAs reported that they had forgotten to fill in the form during or at the end of their shift. The extent of the under-recording was not investigated, but two arguments support our opinion that the effect of under-recording might have been limited. First, the results of this study were congruent with the findings of the previous studies in Belgian nursing homes: except for the dependency level $\mathrm{A}$, the mean total care time spent per resident (data not shown in this paper) increased with a higher dependency level and was $8-14 \%$ higher per dependency level than reported by Cokelaere (1997); 
except for logistic tasks, the proportions of the total care time spent in the five other task categories were not very different from those presented by Mendonck et al. (2000). Secondly, there was no reason to assume that unrecorded data were related to the type of care task or to the professional discipline.

Two issues, which received no attention in the present study, seem important for future research. First, the feelings and opinions of RNs and CAs on their current task assignment and workload need to be investigated. It would be highly relevant to know to which extent individuals of both disciplines feel safe or experience tensions resulting from the organization of the care tasks and the supervision of the work of care assistants in the institution. Secondly, the quality of care given by nurses and care assistants was not measured in the present study. The associations between nurse staffing resources, task demarcation and quality of care need to be clarified in further studies.

\section{Conclusions}

The main conclusions of this study were that the task demarcation between RNs and CAs in Belgian institutions for aged persons was limited to specific care task categories and that most of the time, RNs and CAs performed similar work in the categories of primary care tasks, logistic tasks and supportive tasks. There was evidence that RNs and CAs were spending more time on residents suffering from dementia or on residents with higher dependency. The hypotheses that RNs were focusing on residents with dementia or on residents with higher dependency and that RNs were delegating the care for residents not having dementia or residents with lower dependency levels to CAs were not confirmed.

\section{References}

Arnaert, A., Delesie, L., 1999. Calibration of measurement data: the Belgian Institute of Health Insurance Index of ADL (IJking van meetgegevens: RIZIV A.D.L.-index). ACTA Hospitalia 39 (4), 19-31.

Charlson, M.E., Pompei, P., Ales, K.L., MacKenzie, C.R., 1987. A new method of classifying prognostic comorbidity in longitudinal studies: development and validation. Journal of Chronic Disease 40, 373-383.

Clark, L., Jones, K., Pennington, K., 2004. Pain assessment practices with nursing home residents. Western Journal of Nursing Research 26, 733-750.

Cokelaere, P., 1997. Activity and costs analysis in relation to the care profile [Activiteits- en kostenanalyses in functie van het zorgprofiel]. Unpublished study in the Course 'Omgaan met beperkte middelen in de bejaardenzorg" Centre for Health Services and Nursing Research, Katholieke Universiteit Leuven, Belgium, April 24 and 25, 1997.

Hughes, C.P., Berg, L., Danziger, W.L., Coben, L.A., Martin, R.L., 1982. A new clinical scale for the staging of dementia. British Journal of Psychiatry 140, 566-572.

Katz, S., Ford, A., Moskowitz, R., Jackson, B., Jaffe, M., 1963. Studies of Illness in the Aged. Journal of the American Medical Association 185, 914-919.

Mendonck, K., Van Landeghem, N., Meulemans, H., 2000. Time to care. Analysis of care processes in nursing homes [Tijd voor zorg. Een analyse van de zorgverlening in de sector van de rusthuizen.] Interuniversitair Instituut voor de Studie van de Arbeid, Brussels.

Morgan, D.G., Semchuk, K.M., Stewart, N.J., D'Arcy, C., 2002. Job strain among staff of rural nursing homes. A comparison of nurses, aides, and activity workers. Journal of Nursing Administration 32, 152-161.

Morris, J., 1993. The CDR: current version and scoring rules. Neurology 43, 2412-2413.

Paquay, L., De Lepeleire, J., Schoenmakers, B., Stessens, J., Bouwen, A., van der Burg, M., Di Notte, D., Gazon, R., Ylieff, M., Fontaine, O., Buntinx, F., 2004. The Qualidem project in Belgium. A two-center study on care needs and provision in dementia care: inclusion criteria and description of the population. Archives of Public Health 62, 145-162.

Perry, M., Carpenter, I., Challis, D., Hope, K., 2003. Understanding the roles of registered general nurses and care assistants in UK nursing homes. Journal of Advanced Nursing 42 (5), 497-505.

Rhéaume, A., 2003. The changing division of labour between nurses and nursing assistants in New Brunswick. Journal of Advanced Nursing 41 (5), 435-443.

Roth, M., Tym, E., Mountjoy, C.Q., Huppert, F.A., Hendrie, H., Verma, S., Goddard, R., 1986. CAMDEX-A standard instrument for the diagnosis of mental disorder in the elderly with special reference to the early detection of dementia. British Journal of Psychiatry 149, 698-709.

Siegel, S., Castellan, N.J., 1988. Nonparametric Statistics for the Behavioral Sciences. Mc Graw-Hill, New York.

Thornley, C., 2000. A question of competence? Re-evaluating the roles of the nursing auxiliary and health care assistant in the NHS. Journal of Clinical Nursing 9, 451-458. 